\title{
Poetical potentials: The value of poems in social impact education
}

\section{Simon Rogerson}

For the technologist it is easy to remain in safe technological enclaves with a bespoke language, a community of like minds and a familiar knowledge base. However, progress requires pushing the boundaries, thinking beyond the traditional and the ordinary, and questioning accepted norms. It requires opening of minds. It may surprise the reader that poetry can offer the key to unlock the closed mind.

\section{Introduction}

Over 500 years ago, Leonardo da Vinci wrote that poetry is painting that is felt rather than seen. Such sentiment is echoed in "We can never learn too much about a poem, but always we come back to the work itself, for it exists not only as an historical object and the product of a particular mind and vision, but also in its own right, as an enduring work of art." [1].

As such, poetry challenges us to think beyond the obvious and reflect on what has been, what is and what might be. Poetry can reboot the way in which social impact education is delivered to technologists. According to Rule et al [14] incorporating poetry in science and technology teaching expands the curriculum beyond subject knowledge and process skills. They argue that images and metaphors in poems can clarify and intensify meaning. A poem has many layers and such richness can promote enlightenment

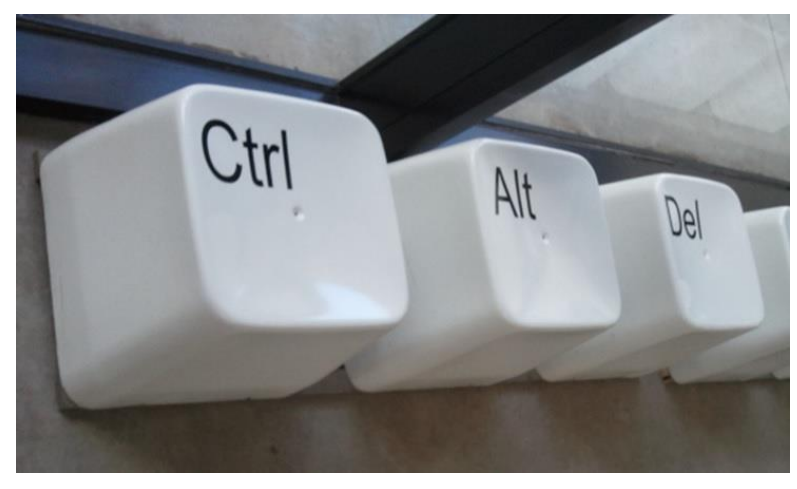
and understanding. Poems can provide meaningful context. This is imperative in ICT education and awareness at all levels for all people as the social impact of technological advances is every increasing. In partnership, computer science and liberal arts educators could offer an exciting new perspective through poetry as an instrument of presentation and discussion as well as in creative exercises for students.

For readers who are unfamiliar with haikus, Trumbull [16] explains that a haiku takes a three line format of 5-7-5 syllables known as a kigo and uses a cutting technique called kire to divide the verse into two parts for contrast or comparison. He argues that the more radical the verse the better the haiku. This is certainly the case when considering the broader issues surrounding the development and use of ICT. For example, in Technological Dependency [11] readers are encouraged to reflect on the deeper meaning of each haiku verse with regard to the ethical and social issues surrounding ICT and how we might address such issues. This approach can also be seen in the haiku winners presented by Barr [3]. 


\section{Information integrity}

An extract from a poem, The Nature of Information by Edward M Housman [5], who was the designer of the Panalog computer conferencing system in the 1970s, illustrates the richness and variety of information and, as such, implies that information integrity must be the watchword for any system designer.

\section{Extract from The Nature of Information}

Information occupies space.

And time.

It takes energy to move information.

Information is necessary for life, for any organized activity.

Information is form without substance, substance without form. Both.

Information, like light, has weight; a gigabyte weighs less than a fingerprint.

The same information can be expressed in different ways: a voice, a letter.

Unlike matter, information can be in many places at once.

A handshake is information. A nod. A look. A sigh.

\section{Societal impact}

Society is now computing dependent and anyone can develop computing systems which might be used by thousands, if not millions of people. Impacts, whether positive or negative, spread rapidly and are very difficult to reverse. Poetry can be effective in highlighting these challenges. It presents the issues from a literary perspective, helping to widen understanding and thereby reducing problems such as computer illiteracy. To illustrate this approach three examples, CTRL ALT DEL, Digi-me and Machine - the final chapter are now presented. Their titles should resonate with technologists and thus start to draw them in.

\section{CTRL ALT DEL}

There is much to reflect upon in CTRL ALT DEL; including the title itself, the first letter of each line and the use of \#tag to finish this short poem [10]. Consider how all these elements fit into a compound view of the world we live in and the increasing irrelevance of the physical form.

Quickly technology pervades

We become subservient

Earth's treasures plundered

Reboot evolution

Type in your fate

You and me transformed into it

\#Keys of the modern world

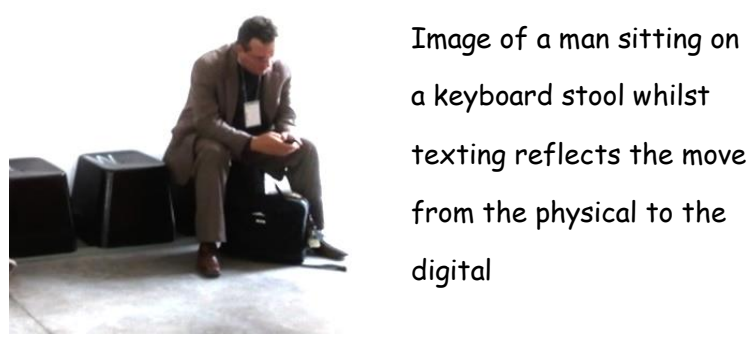




\section{Digi-me}

Rogerson concluded his invited presentation "Digital Being: the modern way to be" with Dig-me, which was simply a two-line poem warning of the dangers unleashed through digitization [12].

Digital being, the modern way to be,

I am the data and the data is me.

\section{Machine - the final chapter}

Such warning of technological advances without careful consideration beyond the technology is the focus of Machine - the final chapter [12]. Lack of proper checks and balances means that advances in computer technology from its inception by pioneers such as Babbage and Lovelace, through to the forefronts of artificial intelligence giving rise to ensuing disaster, potentially moving towards Armageddon as laid out in these three haikus.

\section{Computer}

Bits, bytes, ones, zeros

So Charles and Ada conceive -

IT's Pandora's box

\section{Robot}

Man and beast replaced

Same task over and over -

Objective carnage

\section{Al}

Boolean bible

Artificial ignorance -

Logical ending

\section{Armageddon!}

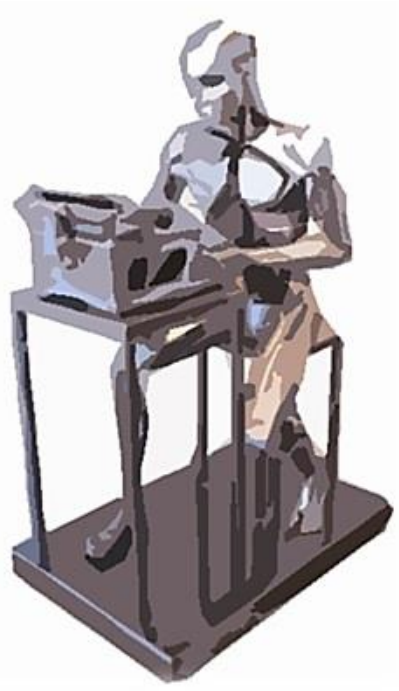

\section{Humor}

The examples discussed so far are poems with a solemn tone. This may seem appropriate given the serious topics being discussed. However, humor is a powerful tool which, when used effectively, can create change and avert disaster. Powell and Andresen found that humor can increase interest, and help to illustrate and reinforce messages [8]. This is a useful instrument to use when teaching technology students about the broader non-technical issues surrounding their discipline. Torok et al explain that humor has the potential to humanize, illustrate, encourage and keep people thinking [15]. A good example of this is "The rime of the ancyent programmer" [6]. Thus, as Bakar and Kumar conclude, the role of humor is twofold: to facilitate understanding and to sustain engagement[2]. The reader is asked to bear this in mind as he or she reads this final example, Chimerical Algorithms, a short story, which at first seems fanciful but underneath lie some serious messages [9]. There is reference to the history of computing 
through Howard (Aiken) and Grace (Hopper), and Kates's eight plus two has translations of ten into binary, octal and hexadecimal in the title. Embedded within this story are two poems. The first is the algorithm Thighs, which is in fact a charter, in poetic format, for computing practitioners. The second is the concluding algorithmic poem that, on reflection, will encourage the reader to adopt lateral thinking in problem solving which is an important approach in computer systems development. This story sits comfortably as a contrast to the more serious take, "Expressing programming algorithms with poetic language" [4].

\section{Chimerical Algorithms}

Ada grew up with computer technology. In fact she was even named after one of its pioneers Ada Lovelace.

Howard, her father had worked on some of the early computers. He had met her mother Grace whilst serving in the armed forces, working on the ADA programming language which was used in military defense applications. Grace was involved in computer programming too and had worked on developing COBOL, the COmmercial BusinessOriented Language.

So it was hardly surprising that Ada had always loved programming for it was in her blood. It was a world of logic, certainty and objectivity. Pouring over lines of code never failed to excite and motivate. She delighted in producing programs which included precisely defined rules to solve problems of all kinds. Back home, Ada relaxed, letting her unchecked imagination create a fantasy world which she shared with her fellow geeks through her Chimerical Algorithms Blog on the Seek Geek social network.

Ada's latest blog entry: Kate's eight plus two - 1010-12-A, contained a group of carefully crafted items:

- Parrot - Nicknamed Pretty Polly, a method for painting the town red, and blue, and yellow, and green, and any other color you care to mention.

- Cherry - Method for cleaning dirty shoes with boot polish so they blossom.

- Rhubarb - A political procrastination tactic similar to filibustering - rhubarb, rhubarb, rhubarb!

- Jealousy - A computer games algorithm used by programmers to incorporate green-eyed monsters into the characters.

- Thighs - The procedural acronym, nicknamed Thighs of Relief, for sustaining a better society
$\circ$ be Truthful
$\circ$ be Honest
○ exhibit Integrity
$\circ$ be Good
$\circ$ act with Humility
$\circ$ be Sensitive

- Carousel - An iterative process for sorting items in a roundabout way.

- Addiction - A method of enunciating certain arithmetic operators.

- Champagne - An artificial intelligence algorithm for identifying personality traits, nicknamed Bubbly.

- Carrot - A process for providing psychological assistance for medics - euphemistically known as What's up doc? 
- Pirate - A method for adding a small amount of tax to circular objects

Ada finished her blog with a little algorithmic poem she thought would amuse her geek friends:

Start
Go home
Eat
Take feet off ground
Let mind wander
Capture imagination
Come back down to earth
Sleep
Waken
Go to work
End

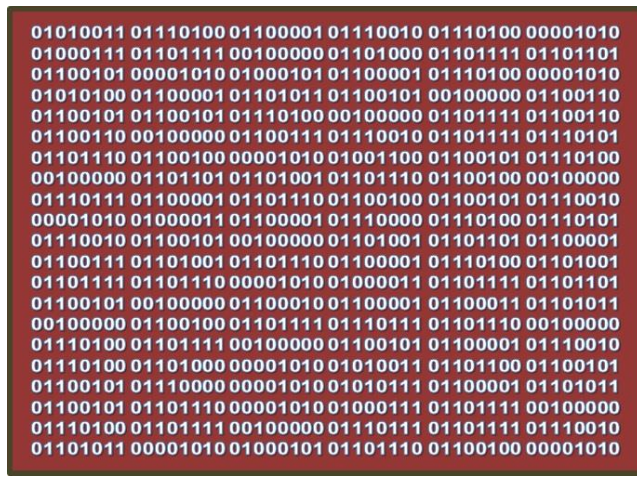

ASCII text of algorithmic poem converted into binary code

\title{
Conclusion
}

Poetry can be the key to unlock the door so the room can be explored. Therefore, why not heed Ada's advice take your feet off the ground and let your mind wander. Who knows what systems you might design, for remember:

\author{
With zeroes and ones \\ You can create infinite \\ Possibilities. [7]
}

\section{References}

1. Anon, How to enjoy a poem. in Pears cyclopaedia, edited by C. Cook, 89th ed. (Book Club Associates, London,1980), M3-M3.

2. Bakar, F. and Kumar, V. The use of humour in teaching and learning in higher education classrooms: Lecturers' perspectives. Journal of English for Academic Purposes, 40 (2019), 15-25.

3. Barr, J. and Barr, S. Haiku Contest Winners. ACM Inroads, 8, 2 (2017), 80-80.

4. Ebrahimi, A. Expressing programming algorithms with poetic language. ACM Inroads, 5, 2 (2014), 16-20.

5. Housman, E.M. The Nature of Information. Bulletin of the American Society for Information Science, 26, 4, (2000).

6. Jenkins, S.B. The rime of the ancyent programmer. Communications of the ACM, 50, 5, (2007), 17-20.

7. Kosa, M. Student choice. in Barr, J. and Barr, S. Haiku Contest Winners. ACM Inroads, 8, 2 (2017), 80-80.

8. Powell, J.P., and Andresen, L.W. Humour and teaching in higher education. Studies in Higher Education, 10, 1, (1985), 79-90.

9. Rogerson, S. Chimerical Algorithms. (5 March 2018). 
10. Rogerson, S. CTRL ALT DEL. (7 May 2019).

11. Rogerson, S. Technological dependency. ACM SIGCAS Computers and Society, 45, 2 (2015), 4-4.

12. Rogerson, S. Digital Being: the modern way to be. presented at 12th IFIP TC9 Human Choice and Computers Conference. (University of Salford, UK, 9 September 2016).

13. Rogerson, S. Machine - the final chapter. posted on PoetrySoup. (2 October 2019);

http://www.poetrysoup.com/poem/machine_the_final_chapter_1185554. Accessed 2019 October 5.

14. Rule, A.C., Carnicelli, L.A. and Kane, S.S. Using poetry to teach about minerals in earth science class. Journal of Geoscience Education, 52, 1(2004), 10-14.

15. Torok, S.E., McMorris, R.F. and Lin, W-C. Is humor an appreciated teaching tool? Perceptions of professors' teaching styles and use of humor. College Teaching, 52, 1, (2004), 14-20.

16. Trumbull, C. An Analysis of Haiku in 12-dimensional Space. Paper for HSA_Meeting 2003.

Professor Simon Rogerson

Centre for Computing and Social Responsibility, De Montfort University

The Gate Leicester, LE1 9BH

srog@dmu.ac.uk 